\title{
Central Apnea
}

National Cancer Institute

\section{Source}

National Cancer Institute. Central Apnea. NCI Thesaurus. Code C116335.

Cessation of air flow due to abnormal central nervous system control. 